\title{
Supply Chain Optimisation in Animal Husbandry
}

\author{
J.M. Bloemhof, C.M. Smeets, J.A.E.E. van Nunen
}

\begin{tabular}{|l|l|}
\hline \multicolumn{2}{|l|}{ ERIM REPORT SERIES RESEARCH IN MANAGEMENT } \\
\hline ERIM Report Series reference number & ERS-2003-043-LIS \\
\hline Publication & May 2003 \\
\hline Number of pages & 30 \\
\hline Email address corresponding author & j.bloemhof@fbk.eur.nl \\
\hline Address & Erasmus Research Institute of Management (ERIM) \\
& Rotterdam School of Management / Faculteit Bedrijfskunde \\
& Rotterdam School of Economics / Faculteit Economische \\
& Wetenschappen \\
& Erasmus Universiteit Rotterdam \\
& P.O. Box 1738 \\
& 3000 DR Rotterdam, The Netherlands \\
& Phone: $\quad+31104081182$ \\
& Fax: $\quad+31104089640$ \\
& Email: info@erim.eur.nl \\
& Internet: $\quad$ www.erim.eur.n! \\
\hline
\end{tabular}

Bibliographic data and classifications of all the ERIM reports are also available on the ERIM website: www.erim.eur.nl 


\section{ERASMUS RESEARCH INSTITUTE OF MANAGEMENT}

REPORT SERIES

RESEARCH IN MANAGEMENT

\begin{tabular}{|c|c|c|}
\hline \multicolumn{3}{|c|}{ BIBLIOGRAPHIC DATA AND CLASSIFICATIONS } \\
\hline Abstract & \multicolumn{2}{|c|}{$\begin{array}{l}\text { The pig husbandry is an important economic sector. In the last decade, major changes have } \\
\text { been made. As a result, farmers came together to introduce the 'Eco Label pig', meeting the } \\
\text { strong consumer and governmental call for high quality, animal friendly and environmentally } \\
\text { friendly food. The market for Eco Label food is expected to grow enormously in the next years, } \\
\text { asking for the development of an efficient and effective supply chain consisting of farmers, } \\
\text { slaughter houses, wholesalers and retailers. We present some mathematical models to support } \\
\text { decision making and evaluation of a large number of growth scenario's, using cost minimization } \\
\text { given a number of Eco Label conditions. }\end{array}$} \\
\hline \multirow{3}{*}{$\begin{array}{l}\text { Library of Congress } \\
\text { Classification } \\
(\mathrm{LCC})\end{array}$} & $5001-6182$ & Business \\
\hline & $5201-5982$ & Business Science \\
\hline & HD 2748 & Vertical Integration \\
\hline \multirow{4}{*}{$\begin{array}{l}\text { Journal of Economic } \\
\text { Literature } \\
\text { (JEL) }\end{array}$} & M & Business Administration and Business Economics \\
\hline & M 11 & Production Management \\
\hline & R 4 & Transportation Systems \\
\hline & L 22 & Vertical Integration \\
\hline \multirow{4}{*}{$\begin{array}{l}\text { European Business Schools } \\
\text { Library Group } \\
\text { (EBSLG) }\end{array}$} & $85 \mathrm{~A}$ & Business General \\
\hline & $260 \mathrm{~K}$ & Logistics \\
\hline & $240 \mathrm{~B}$ & Information Systems Management \\
\hline & $260 \mathrm{~K}$ & Logistics \\
\hline \multicolumn{3}{|c|}{ Gemeenschappelijke Onderwerpsontsluiting (GOO) } \\
\hline \multirow[t]{4}{*}{ Classification GOO } & 85.00 & Bedrijfskunde, Organisatiekunde: algemeen \\
\hline & 85.34 & Logistiek management \\
\hline & 85.20 & Bestuurlijke informatie, informatieverzorging \\
\hline & 85.34 & Logistiek management \\
\hline \multirow[t]{3}{*}{ Keywords GOO } & \multicolumn{2}{|c|}{ Bedrijfskunde / Bedrijfseconomie } \\
\hline & \multicolumn{2}{|c|}{ Bedrijfsprocessen, logistiek, management informatiesystemen } \\
\hline & \multicolumn{2}{|c|}{ Logistiek management, bedrijfskolommen, vleesverwerkende industrie, ketenbeheer } \\
\hline Free keywords & \multicolumn{2}{|c|}{ Logistics, Network configuration, Agricultural logistics, Supply chain management } \\
\hline
\end{tabular}




\title{
Supply Chain Optimisation in Animal Husbandry
}

\author{
J.M. Bloemhof, C.M. Smeets, J.A.E.E. van Nunen \\ Faculty of Business Administration, Erasmus University Rotterdam, \\ PO Box 1738, 3000 DR Rotterdam, The Netherlands
}

\section{Draft / Version February 2003}

\begin{abstract}
The pig husbandry is an important economic sector. In the last decade, major changes have been made. As a result, farmers came together to introduce the 'Eco Label pig', meeting the strong consumer and governmental call for high quality, animal friendly and environmentally friendly food. The market for Eco Label food is expected to grow enormously in the next years, asking for the development of an efficient and effective supply chain consisting of farmers, slaughter houses, wholesalers and retailers. We present some mathematical models to support decision making and evaluation of a large number of growth scenario's, using cost minimization given a number of Eco Label conditions.
\end{abstract}

Keywords. Logistics, Network configuration, Agricultural logistics, Supply chain management.

\section{Introduction}

The pig husbandry in the Netherlands has considerably changed during recent years. Large scaling up took place leading to the disappearance of small firms and the increase of big firms. Further, the volume of the pig husbandry decreased as a whole with about 20 percent in five years time and the image of the sector worsened due to diseases, restricting legislation and fodder scandals. In order to compete these threats, the pig husbandry introduced the Eco Label Pork, which is environmentally and animal friendly produced and of high quality. 
The Dutch Foundation of Eco Labeling originated in 1992 as a co-production of government, producers, consumers, retail and environmental organizations. It is the Dutch competent body for the European Eco Label. The aim is to stimulate animal and environmentally friendly production using a protected label. A product awarded with the Eco Label is much more friendly to the environment compared to most similar products. The Eco Label can be found on photocopying paper, labels, chairs, shoes, linoleum, writing pads, toilet paper, car polishing products, carwashes, cat litter, organic waste base plates, plants and flowers, bread, apples, pears, onions, barley, wheat, apple juice, potatoes and other things.

In the mean time the initiators of the Eco Label Pork, producers, supply chain members and NGOs have gained experience with the development of the Eco Label Pork as a socially sound, practically applicable and independent alternative for the usual pork production. At the moment, about 26000 pigs a year are produced, treated and sold under Eco Label. Specific Eco Label requirements have to do with the farming and the logistics within the supply chain (e.g. restrictions on the maximum travel time from farmer to slaughter house). At the moment, the purpose of the parties concerned with the Eco Label Pork is to obtain a real sustainable supply chain as well as to stimulate the volume of the production and sales of the Eco Label Pork.

Increasing the volume of production and sales of a relatively new product asks for the development of an efficient and effective distribution network in the supply chain. The subject of this article is to obtain insight in the efficiency of distribution networks for the Eco Label Pork in the long run, by minimizing costs given specific Eco Label related restrictions.

Section 2 describes the problem framework, section 3 focuses on the methods to analyze distribution systems and section. Section 4 introduces the model framework whereas section 5 contains the results of the scenario analysis. Finally, section 6 holds the conclusions. 


\section{Problem Description}

A lot of effort has been made to recruit pig-farmers for the Eco Label pigs supply chain. The Eco Label organization expects a huge growth of the production of the Eco Label pigs. This is not only expected by the organization, but also necessary to get the supply chain profitable and the consumer price not much higher than the price for ordinary pig meat.

Growth of production is not the only method for reaching this objective. A complementary method is getting the supply chain processes more efficient. The supply chain starts at the pig farmers. The pigs are distributed to slaughterhouses where they are processes into carcasses. The carcasses are distributed to wholesalers, and the Eco Label Pork is distributed to butchers (and in the future hypermarkets), where the pork is sold to customers (see Figure 1).

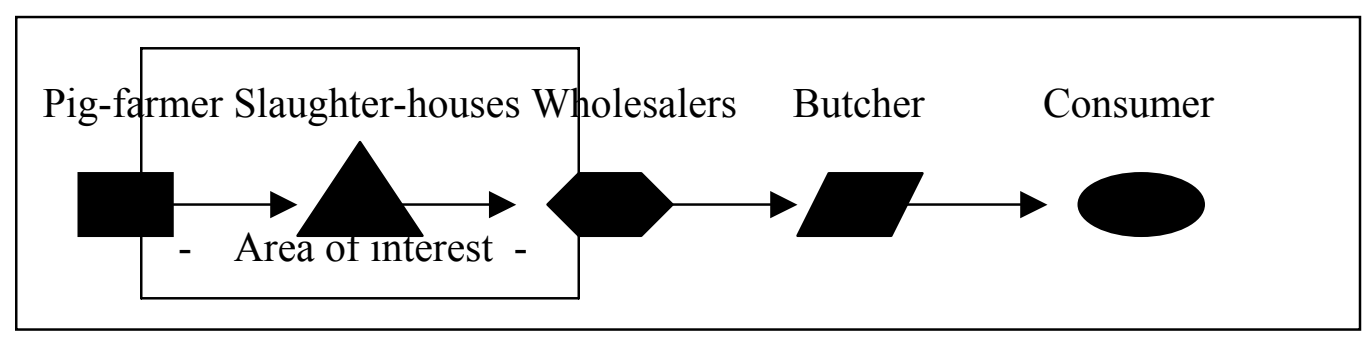

Figure 1: Distribution structure for the Eco Label pigs

The production of the Eco Label pigs momentarily is 26000 pigs a year. It is hard to make demands on the slaughterhouses by this relative low production. The distribution structure of the supply chain is rather straightforward because of the concentration of the production in the South of the Netherlands. Only one wholesaler and one slaughterhouse are part of the supply chain. The intention of the Eco Label organization is to let the production grow to one million pigs a year over the next five years. The structure will then become far more complicated. The question is: which distribution structure is at the long term most efficient?

The research objective is to:

Provide insight in the efficiency of the distribution network of Eco Label pigs at the long term, by minimizing the relevant costs. 
We focus on the following research questions:

- How is an efficient distribution structure set up?

- Which methods and techniques fit to analyze distribution structures?

- Which aspects have to be taken into account in finding an efficient distribution structure?

- Which conclusions can be drawn based on the efficiency analysis of the distribution structure?

\section{Distribution systems}

The distribution system for Eco Label Pigs can be designed from different perspectives, depending on the structure that already exists and the objectives underlying the distribution system. If a completely new network has to be developed, different answers are needed compared to the case where the Eco Label Pigs can be distributed via an existing network. In this section we investigate some important location questions and motivate the choice for our solution procedure based on the characteristics of the problem area.

\subsection{Location Problems}

In this paragraph we describe the important questions dealing with location decisions. Designing a distribution network consist of a number of location decisions. These decisions contain the allocation of production, storage, capacity and transport related facilities. In a location problem, decisions have to be made on the number of facilities, at which location, with what production so that the demand gets fulfilled and the objective is being optimized. Location decisions can be split up in five important questions:

1. Number: How many locations should be placed?

2. Location: Where should the facilities be located?

3. Facility role: What role should each facility play? What processes are performed at each facility? 
4. Capacity allocation: How much capacity should be allocated to each facility?

5. Market and supply allocation: What markets should each facility serve? Which supply sources should feed each facility?

All location decisions influence each other. That is why it isn't possible to take one decision apart from the others (Chopra and Meindl, 2001).

\subsection{Characterization of the Eco Label Location Problem}

The research exists out of the following questions:

- Which slaughterhouse or slaughterhouses can best be used? How many of them, at which location?

- Which wholesalers can be best be used? How many, at which location?

- Which Pig-farmers are allocated to which slaughterhouses? Which wholesalers are allocated to which slaughterhouses?

The location and number of pig-farmers are not included in the location decision, because these are future data and can hardly be influenced by the Eco label organization.

A few important differences can be found between the Eco Label location problem and general location problems in scientific literature:

1. The main difference is the independence of the facilities being analyzed. The Eco Label organization has a coordinating role in the supply chain, but does not own the chain. Therefore, they don't have much influence, especially towards the slaughterhouses and wholesalers.

2. Coherent with the first difference, in the literature most location problems exist of facilities that have to be build. Building a facility has great investing costs, which does not apply here, because in this case the facilities already exist. As a result it is fairly easy to switch facilities. 
3. The investigated supply chain consists for one part out of living material and for another part out of perishable products, so no stock costs arise in this case. Most location problems deal with tangible non-living products allowing for stocks.

4. In general the production facilities are big factories, of which a few are used, but with a large production. In the pig-industry production facilities are many, the pig-farmers, but with a small production. Combined with the fact that the exact location of future pigfarmers is not known yet, the individual coordinates of the pig-farmers cannot be used in the model. A solution could be clustering the pig-farmers, for example by region.

5. The last difference between the case and the literature is push versus pull. In this location problem, the objective is not to fulfill demand (pull model), but to deliver production (push model). The butchers (i.e. the demand side of the supply chain) have agreed in a covenant to take all Eco Label Pork produced in the supply chain. Therefore the supply side determines the flows in the network structure.

\subsection{Characteristics of Location Problems}

Many publications exist on location problems, due to the large diversity of the problem settings. This diversity proceeds from a variety of applications, underlying objectives and characteristics of the problem. The application can vary from location selection of factories, warehouses and distribution centers to allocating space in a factory to machinery, the cafeteria, tool room and toilets.

The first distinction is related to the nature of the objective, which can be either qualitative or quantitative. Qualitative objectives are relative easy to understand and therefore often used. Examples of qualitative factors are infrastructure, presence of labor (quality as well as quantity), presence of land, nearness of markets and suppliers etc. (Chopra and Meindl, 2001) and (Sule, 2001). A well known example of a qualitative method is the ranking method. With this method the managing team selects factors that they think are important for the location decision being made. Also, a maximum weight for each factor is determined on a scale from 0 to 100 . Each location is given a score for each factor from 0 to the maximum weight. The location with the highest overall score is favorable. The qualitative methods are fairly easy to understand and also 
have as advantage the possibility of analyzing multiple factors at the same time. The disadvantage of these methods is the subjectivity through the influence of personal opinions of the management team (Heizer and Render, 2001).

A qualitative method is suitable for developing distribution networks if the network is completely new or the network has to fulfill multiple objectives, for example with environmental burdening. This is essential with building facilities, if the environment, licenses and many strategic plans have to be taken into account.

This method would be very worthwhile if no network structure exists for the Eco Label Pork. In the current situation, other questions have to be assessed: a selection is to be made out of existing wholesalers and slaughterhouses, not a selection of locations for building them. Because of this a quantitative method, minimizing a mathematical formula consisting of quantifiable costs is more suitable. In the remaining of the article we focus only on quantitative methods.

Within quantitative methods, we distinguish continuous and discrete location problems. A discrete location problem has a finite set, a given number of possibilities, for the possible locations (Barros and Labbé, 1994). A problem is continuous if all locations in a certain space are possible, i.e. the possible locations form an infinite set (Plastria, 1995). Again, these methods can be very useful in developing a distribution network without any history. These type of methods can also be used if e.g. butchers and customer areas have to be located. In our problem setting, the wholesalers and slaughterhouses that have to be selected already exist. There is no free choice of locations to build these facilities, so this specific problem has a final set of possible locations and is thereby a discrete problem.

Another characteristic of quantitative methods is the variety in mathematical objectives. Five categories can be mentioned (Sule, 2001):

1. $p$-Median problem

2. $p$-Center problem

3. Uncapacitated facility location problem (UFLP)

4. Capacitated facility location problem (CFLP) 


\section{Quadratic assignment problem}

The $p$-median problem has the objective to place $p$ facilities at $p$ locations at minimum costs. The costs can be defined as value of time, money, distance, etc. This problem is also called minisum or Weber problem (O'Kelly, 1995).

The $p$-center problem or minimax problem has the objective to place $p$ facilities at $p$ locations minimizing the maximum distance from a facility to a point of demand. This type of objective is typical for locating emergency services, such as fire stations, police and hospitals (O'Kelly, 1995).

The uncapacitated facility location problem (UFLP) (Harkness and ReVelle, 2003) has the same objective as the minisum problem, but the cost formula contains a fixed cost component, i.e. also costs are related to the facilities themselves. Because the capacity of each facility is infinite, it is never optimal to allocate a specific demand to multiple facilities.

The Capacitated facility location problem (CFLP) (Harkness and ReVelle, 2003) is the same as UFLP, except for the capacity constraint.

The Quadratic assignment problem defines problems, where $n$ facilities, such as $n$ machines with their own production flow, at $n$ locations at the same time have to be placed to minimize the costs.

Depending on the cost structure, different problem categories are suitable. If all cost components deal with transportation, a p-Median or p-Center problem will satisfy. If some of the supply chain costs are related to the facilities, the facility location problem suits best. If the facilities have restricted capacities, due to the fact that these facilities already exist, the problem can be defined as a Capacitated facility location problem (CFLP).

The central method for quantitative analysis is linear programming. This method is used very often. Linear programming (LP) is a well-known technique, thanks to a very fast algorithm (the simplex-algorithm). A basic LP-model can be used to solve location problems with existing facilities and only costs related to flows. These costs can be expressed as money, but also distance or time. The models can be used for example to solve discrete $p$-center en $p$-median problems. 
For the UFLP and CFLP, the basic LP-model is extended with an added integer decision variable, locations can be "open or closed". The costs related can be building the facility or rent. This method, Mixed integer linear programming (MILP), deals with both continuous and integer values. With the LP and MILP most problems can be resolved.

The next characteristic is the number of levels of the location problem. A single-level location problem has to locate one level of locations, whereas other locations are fixed. If multiple facilities of different nature have to be located, such as warehouses and factories (2-level), the problem is a multi-level problem.

A last characteristic is the number of periods in the problem. Location decisions are in general long term of nature, because of the investment costs. If an organization expects few changes in the market situation, the problem often is analyzed as a single period problem, i.e. with one set of input data. The counterpart of a single-period problem is a multi-period facility location problem (MFLP). This problem suits organizations with very variable market or cost conditions over time. With this problem, location decisions have to be made about the number of facilities to be located, with what production, in each period for a known demand. These decisions are made up front, with a rolling horizon in which the values of the variables of the problem can change (Canel and Sidhartha, 1999). Publications on multi-period facilities location problems using exact and heuristic methods are overviewed in e.g. (Canel and Sidhartha, 1999). Also, a couple of studies exist, combining mixed-integer programming with dynamic programming to solve the MFLP (Canel and Sidhartha, 1999). With this method, first all individual periods are optimized, then the overall solutions is analyzed for the whole time horizon with dynamic programming.

\subsection{Choice of Problem Characteristics for the Eco Label Location Problem}

Looking back at the characterization of location problems we can see that:

i. The wholesalers and slaughterhouses that have to be selected already exist. There is no free choice of locations to build these facilities, so this specific problem has a final set of possible locations and is thereby a discrete problem. 
ii. A part of the supply chain costs are the slaughtering costs. These costs are related to the facility, the slaughtering house. The slaughterhouses as well as the wholesalers have restricted capacities. This of course is related to the fact that these facilities already exist. This is why the problem is defined as a Capacitated facility location problem (CFLP), solved by mixed integer programming.

iii. The research has a strategic character. The objective is an analysis of the distribution network in a time horizon of five year. This means that the problem is a multi-period location problem with five periods. Because of the lack of investment costs (the facilities already exist so do not have to be built), it is rather easy to switch between facilities. If the supply from a region is high enough (about 2000 pigs a week, cq. 100000 pigs a year), changing slaughterhouses is possible without losing time or money. These circumstances are different from traditional cases in the literature. This is the first reason to choose for the method with the single-period solutions. Another reason is the objective to give insight in the efficiency of the supply chain, which is obtained by analyzing the single- period solutions in combination with the optimal solution for the whole time horizon. Finally, also one-period second best solutions are very interesting to analyze. The eco- label pigs get slaughtered first thing in the morning, to avoid stress and to get the flesh as fresh as possible by the wholesaler. Therefore, it can be better for the Eco Label to use more slaughter houses than in the optimal solution, because the more slaughter-houses used, the sooner the pigs get slaughtered, the better the flesh quality and the fresher the meet that gets to the wholesalers.

iv. In the Eco Label problem, a selection of slaughterhouses and wholesalers has to be made. As a result the problem contains two levels.

Summarized the Eco Label Location problem is a discrete two-level multi-period capacitated facility location problem (see Figure 2).

This research is focused on Eco Label pigs, "ordinary" pigs from traditional farming are not taken into consideration. As the population of Eco Label pigs compared to the pig population in total will stay less than 6 percent, changes in the distribution structure for Eco Label pigs will not cause large changes in the distribution structure for ordinary pigs. 
We focus on the distribution between farmers and slaughterhouses and the distribution between slaughterhouses and wholesalers. Processes at the butchers and the consumers are not taken into account for several reasons:

- Butchers are free to choose their own wholesalers. The Eco Label organization has marginal power to change these decisions. The Butchers union has obliged themselves to buy the eco label pork through a Covenant with the farmers, the slaughterhouses and the wholesalers. Therefore, whatever the production of the pork is, there will be a demand somewhere at the butchers.

- The consumers due not influence the choice of slaughterhouses and wholesalers.

- The processes inside the pig-farmers, wholesalers en slaughterhouses are not included, exception for relevant distribution costs (see Figure 1).

Environmental costs arise mainly at the farm (ammonia emission in the air, manure excesses, etc.), the environmental costs of transporting pigs and carcasses are very low compared to these emissions, and therefore not a main issue in this research.

Summarizing, the main questions to be answered are: how many slaughterhouses to use in the coming five years, and which ones, and how many wholesalers to use and which ones to get an efficient supply chain.

\section{Model Framework}

The objective of the research is to develop an efficient distribution structure for the Eco Label Pigs, minimizing logistical costs. At first glance, this objective seems not appropriate for an Eco Label product, one would expect also environmental costs involved. However, from literature it appears that the environmental burden of the pig sector appears at the farm (mineral excesses) and not during the transportation and processing from pig to pork (Blonk, 2001). Eco Label requirements to protect the environment and animal well-being do appear in the model. Firstly, only slaughterhouses and wholesalers in the Netherlands are allowed to take Eco Label pigs and 


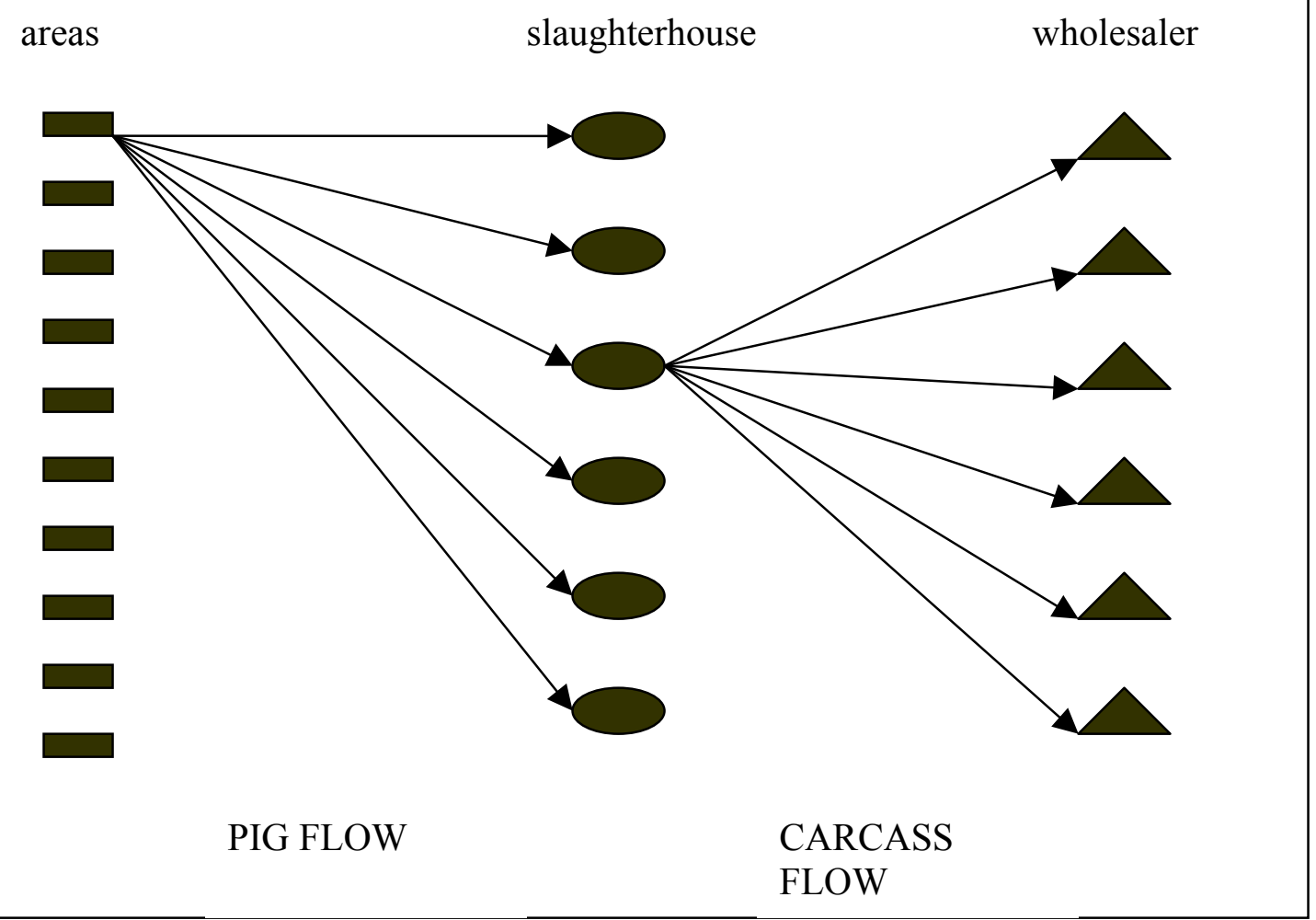

Figure 2: Overview of the Problem Structure

pork. In traditional pig husbandry, a large amount of the living pigs are transported to Spain, Italy and other European countries to be slaughtered over there, and brought back as pork to be consumed in the Netherlands. This occurs because farmers get a higher price abroad and it is cheaper to transport pigs than pork that has to be cooled. Secondly, living pigs are allowed to be transported only 200 kilometres and are processed in the slaughterhouses early in the morning to avoid stress (whereas on average 500 kilometres is normal in traditional pig husbandry, which gives a real improvement in animal well-being).

Therefore, the main question of the research is objective of the model to be built is: minimize relevant costs (both transportation costs and facility costs), given a finite set of locations for slaughterhouses and wholesalers with given capacities and a set of special Eco Label conditions. In order to answer the general research questions raised in section 2, and worked out specifically in section 3, the following elements of the modeling process must be considered:

- Preparing the data for input into the model 
- Modeling specific transportation and slaughtering costs

- Making assumptions

- Notation

- Formulating the mathematical model

\subsection{Preparing the data for input in the model}

To evaluate long-term scenarios, a number of data has to be prepared in advance.

i. Regions. For calculating the transportation costs from the farmers to the slaughterhouse and from the slaughterhouse to the wholesaler, a regional division of the Netherlands is necessary. Firstly, because we analyse future scenarios in which the precise locations of future farmers is not known. Secondly, the producing farmers themselves are presumably too small in size, especially in the first years of the forecast when the volume of the Eco Label pig population is not that high, and too many to deal with. Therefore it is reasonable to aggregate the producing farmers to about 40 areas of contracted municipalities.

ii. Year productions. In order to forecast growth scenarios for Eco label Pigs, it is necessary to gather data on the current spread of pig production in the Netherlands. The year production of a region is calculated by multiplying the cage capacity in a region with a cycle factor (i.e. the number of times the cage is occupied on average during a year).

iii. Forecast of the population. We assume an exponential growth in the production of Eco Label pork. At the start the production of eco label pigs is low, with a rather high entry-barrier. As the production and sales of eco label pigs becomes more accepted, more and more farmers will switch to the eco label, decreasing the entry barrier. This so-called snowball effect can best be modelled by an exponential growth model, i.e.

$$
Y^{i}{ }_{t}=Y^{i}{ }_{0} \bullet g^{t}
$$

with

$Y_{t}^{i} \quad$ : the number of pigs in area $i$ in period $t$

$Y_{0}^{i} \quad$ : the number of pigs in area $i$ in period 0 
$g \quad:$ the growth factor (constant)

The number of Eco Label pigs in period 0 is assumed to be 26000 . If e.g. the goal is to arise at one million pigs a year after 5 years, the growth factor is 2.07. At the moment only three areas in the South East of the Netherlands produce Eco Label Pigs, therefore the regional spread of the traditional pig husbandry is used to assign values to the various regions in the first year.

\subsection{Modelling costs}

In the pig husbandry, living material is transported from A to B. As a result, almost no inventory takes place at the processes in the chain, i.e. the farm, the slaughterhouse, and the wholesaler. Therefore, these processes can be qualified as cross-dock processes. Inventory is only for a couple of hours until a truck is available for transport and never more than 12 hours. Relevant costs are transportation costs and facility costs. The inbound transportation costs occur from the farm to the slaughterhouses. Outbound transportation costs occur from slaughterhouses to wholesalers. The fixed and variable costs at the slaughterhouse depend highly on economies of scale.

4.2.1 Transportation costs 
Transportation costs for pigs are calculated per load. They depend on the distance, the duration of load, unload and transportation, and the number of pigs to be transported. On average, a load has about 100 pigs. Costs per load can be quantified as: $1.363+0.0056 *$ kilometers of the outward journey. Further costs are penalty costs: if a pig is transported over more than 100 kilometers, the change of dying during transportation is significant (1\%). Capital loss of a pig is about $€ 125$ per load. If pigs have to be transported more than 200 kilometers, a penalty cost of $€ 100$ per pig is added, making this kind of transport very unlikely. The Eco Label organization decided to select 14 slaughterhouses as suitable for the Eco Label chain.

The Eco Label Pork is sold via a channel of selected butchers. This organization of selected butchers recommends about 13 wholesalers to use. These wholesalers are the set of possible locations in the model with given capacity. Transportation costs are calculated based on the duration of the transport, defined as load and unload, outbound journey and return journey. Load and unload take about 90 minutes ( $€ 50$ per hour), load unit is about 150 carcasses.

\subsubsection{Slaughtering costs}

Traditionally, farmers sell pigs to the slaughterhouse and get a certain price per kilogram in return. Costs of slaughtering are already part of this price. For Eco Label pigs a different structure is valid. The Eco Label organization buys the approved pigs back from the slaughterhouse to sell them to the wholesalers. Therefore only the slaughtering costs have to be taken into account. Because all other costs are calculated in number of pigs, an average amount of kilograms per pig is assumed. Slaughtering costs have economies of scale. The more pigs to slaughter in a year, the less the slaughter costs are. In practice the calculation has many graduations. If the amount of pigs is higher, the cost price for all pigs in a load is lower. Because for each possible interval a different cost price can be calculated, this is hard to model in a mixed integer linear programming model. Therefore this situation is simulated by using a piecewise linear cost function with a fixed and a variable cost component (see Figure 3). The variable cost part can be found in Table 1. The variable costs for a load of 100000 pigs is e.g.: $52000 * 11.5+48000 * 9.5$. Cost reductions mentioned in Table 1 are higher than the cost reductions in practice to compensate for the fact 
that only a small number of segments is chosen in the cost function, with a fixed price in each segment.

\begin{tabular}{|l|l|}
\hline \# slaughters a year in one slaughterhouse & Costs per pig $(€)$ \\
\hline $0-52000$ & 11.5 \\
\hline $52000-130000$ & 9.5 \\
\hline$>130000$ & 6.5 \\
\hline
\end{tabular}

Table 1: Economies of scale in variable slaughtering costs

The slopes of the segments are $c_{1}, c_{2}$, and $c_{3}$. The intercepts $K_{2}$ and $K_{3}$ are determined from the formula $\mathrm{K}_{\mathrm{i}+1}=\mathrm{K}_{\mathrm{i}}+\mathrm{c}_{\mathrm{i}} \mathrm{U}_{\mathrm{i}}-\mathrm{c}_{\mathrm{i}+1} \mathrm{U}_{\mathrm{i}}$. By definition, $\mathrm{c}_{\mathrm{i}+1} \leq \mathrm{c}_{\mathrm{i}}$, as the cost curve represents an activity with economies of scale (compare Harkness and Revelle, 2003).

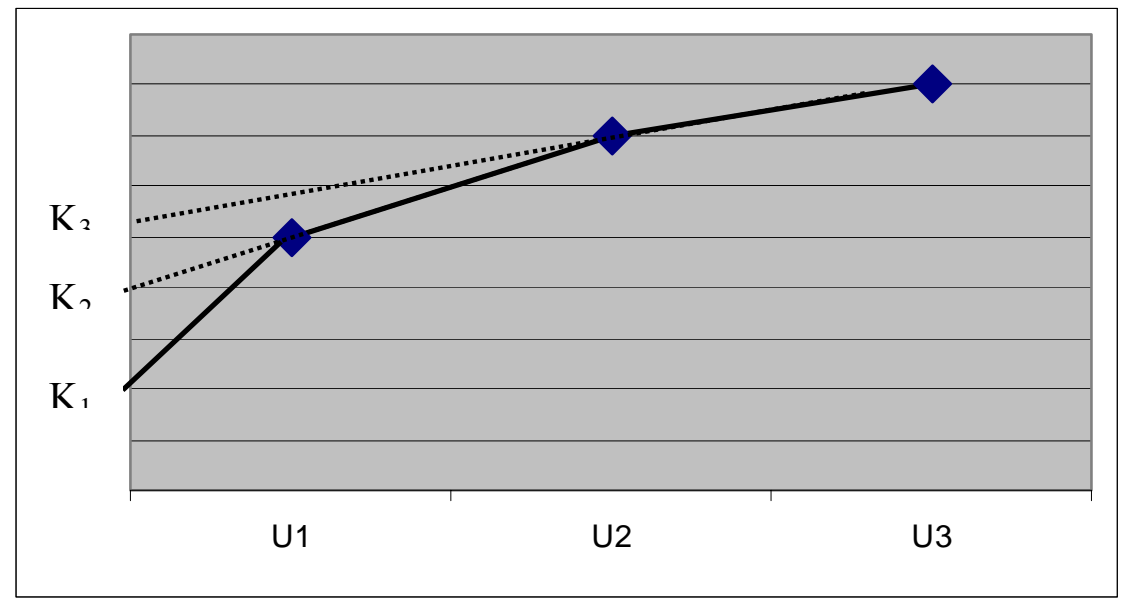

Figure 3: Piecewise linear cost function

This cost curve can be represented as follows:

Define:

1 if $U_{i-1}<\mathrm{x} \leq U_{\mathrm{i}}$

$\mathrm{y}_{\mathrm{i}}=$

0 else

$\mathrm{x}$ if $\mathrm{U}_{\mathrm{i}-1}<\mathrm{x} \leq \mathrm{U}_{\mathrm{i}}$

$\mathrm{x}_{\mathrm{i}}=$ 
0 else

and

$\operatorname{minimize} \mathrm{K}_{1} \mathrm{y}_{1}+\mathrm{K}_{2} \mathrm{y}_{2}+\mathrm{K}_{3} \mathrm{y}_{3}+\mathrm{c}_{1} \mathrm{x}_{1}+\mathrm{c}_{2} \mathrm{x}_{2}+\mathrm{c}_{3} \mathrm{x}_{3}$

subject to

$\mathrm{x}_{1} \leq \mathrm{U}_{1} \mathrm{y}_{1}$

$\mathrm{x}_{2} \leq \mathrm{U}_{2} \mathrm{y}_{2}$

$\mathrm{x}_{3} \leq \mathrm{U}_{3} \mathrm{y}_{3}$

For the slaughtering costs we know the following values:

$\mathrm{U}_{1}=52000 \quad \mathrm{c}_{1}=11.5$

$\mathrm{U}_{2}=130000 \quad \mathrm{c}_{2}=9.5$

$\mathrm{U}_{3}=$ infinity $\quad \mathrm{c}_{3}=6.5$

This leads to the following values for $\mathrm{K}$ :

$\mathrm{K}_{1}=0$ : no costs if there is no pig to slaughter

$\mathrm{K}_{2}=0+11.5 * 52000-9.5 * 52000=104000$

$\mathrm{K}_{3}=104000+9.5 * 130000-6.5 * 130000=494000$

Comparing this piecewise linear function to a cost function with even price decrease leads to Figure 4. For example, with 100000 pigs, in both cases the slaughtering costs are $€ 10,54$. 


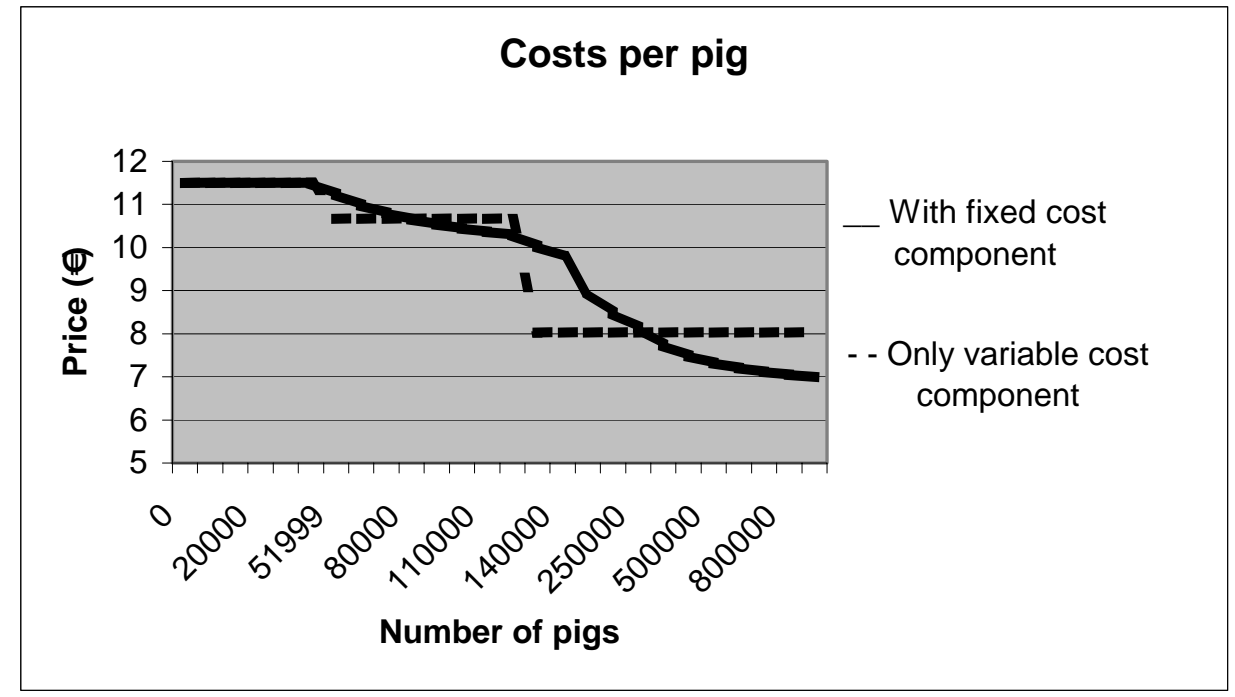

Figure 4: Comparison between even price decrease and segmented price decrease.

Now the cost functions have been defined, next section describes the mixed integer linear programming model in total.

\subsection{Notation, Decision variables and the MILP model}

Indices:

$i \in I=$ set of producing areas

$j \in J=$ set of slaughterhouses

$k \in K=$ set of wholesalers

$t \in T=$ set of breakpoints in the Piecewise Linear Cost Curve (see section 4.2)

Parameters:

$a_{i}=$ production of pigs in area $i$ (\#pigs)

$b_{j}=$ maximum capacity at slaughterhouse $j$ (\#pigs)

$m_{k}=$ maximum capacity of wholesaler $k$ (\#carcasses)

$c_{i j}=$ unit transportation costs between area $i$ and slaughterhouse $j(€ /$ pig)

$d_{j k}=$ transport time per shipment including load and unload from slaughterhouse $j$ to wholesaler $k$ based on a unit load of 150 carcasses (\#minutes)

$h=$ costs for transporting carcasses $(€ /$ minute $)$ 
$g_{j k}=$ transportation costs from slaughterhouse $j$ to wholesaler $k(€ /$ carcasse $)$

$l_{t}=$ variable slaughtering costs for breakpoint $t$

$v_{t}=$ number of pigs at breakpoint $t$

$k_{t}=$ fixed slaughtering costs for breakpoint $t$

Note that

1. $g_{j k}=2 * d_{j k} / 150 * h$, because transportation costs have to be assigned to both the forward and return journey;

2. $k_{t+1}=k_{t}+l_{t} * v_{t}-l_{t+1} * v_{t}$

Decision variables:

$W_{i j}=$ number of pigs transported from area $i$ to slaughterhouse $j$ (continuous)

$X_{j k}=$ number of carcasses transported from slaughterhouse $j$ to wholesaler $k$ (continuous)

$U_{j t}=$ number of pigs for slaughterhouse $j$ in cost segment $t$ (semi-continuous)

$Y_{j t}=$ boolean, 1 indicates $\mathrm{v}_{\mathrm{t}-1}<\mathrm{U}_{\mathrm{jt}} \leq \mathrm{v}_{\mathrm{t}}$ else 0 , i.e. the cost segment $t$ in slaughterhouse $j$ is relevant or not (bilinear).

The Eco Label Location model can now be formulated as follows:

$$
Z=\min \sum_{i} \sum_{j} c_{i j} W_{i j}+\sum_{j} \sum_{k} g_{j k} X_{j k}+\sum_{j} \sum_{t}\left(k_{t} Y_{j t}+l_{t} U_{j t}\right)
$$

Subject to:

$$
\begin{aligned}
& \sum_{j} W_{i j} \geq a_{i} \\
& \sum_{i} W_{i j} \leq b_{j} \\
& \sum_{i} W_{i j}=\sum_{j} X_{j k} \\
& \sum_{j} X_{j k} \leq m_{k}
\end{aligned}
$$




$$
\begin{aligned}
& \sum_{i} W_{i j}=\sum_{t} U_{j t} \\
& U_{j t}<v_{t} Y_{j t} \\
& W_{i j}, X_{j k} \geq 0 \\
& Y_{j t} \in(0,1) \\
& U_{j t}=0 \longrightarrow \text { or } \longrightarrow v_{t-1} \leq U_{j t}<v_{t}
\end{aligned}
$$

\section{Analysis of the scenarios}

Two different scenarios have been analyzed. The first scenario assumes equal growth through all of the Netherlands, of course with the relation to the size of the normal pig production in mind. This scenario has been analyzed for both an optimistic growth to a production of one million Eco

Label pigs in the next 5 years and a less optimistic production growth to just a half million pigs in the next 5 years.

In the second scenario the growth of production is assumed only to be in the south of The Netherlands. This scenario has been chosen because of the present production of eco label pigs is just located there. The organization has also more business relations in the Southern Netherlands, not just with the farmers but also with the food producer, who is of great influence on the farmers. So the chance of convincing a farmer to join the Eco Label is much more likely to succeed in that region. This scenario is also analyzed for the rather positive and the less positive production growth. 
Because of the rather insecure data about the slaughtering costs, a sensitivity analysis was carried out on this subject. The result of the analysis of the scenario with a growth throughout

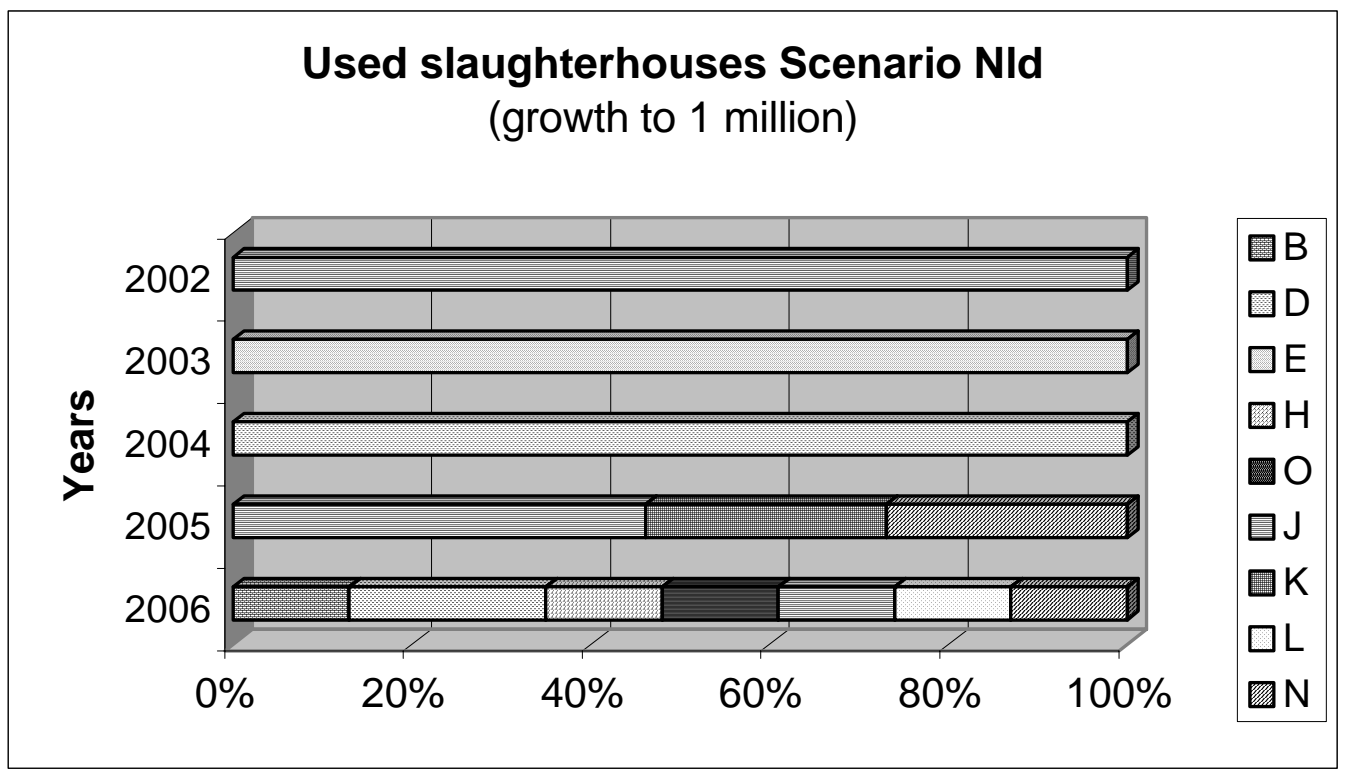

Figure 5: Slaughtering houses in the optimal solution for each year

the Netherlands to one million eco label pigs is given in Figure 5. It shows the number slaughtering-houses used in the optimal solution for each year, and the share of each used slaughtering-house of total slaughter. The results show that in the later years, with higher production, the use of more and more slaughtering houses is optimal. In 2002 only one slaughtering house is used in the optimal solution, while in 2006 seven slaughterhouses are used. The scenario with a growth to half a million eco label pigs has great resembles with the scenario of one million. Only in this scenario's almost in each year just one slaughterhouse is used in the optimal solution, with exception of the last year, 2006 with a production of half a million pigs, three different slaughterhouses are used.

The growth of the number of slaughterhouses used if the production is growing can be explained with the slaughtering cost function. Large financial advantages arise for getting the number of slaughters per slaughtering-house at the breakpoint of the piecewise linear cost function, often more advantage can be made here than with the transportation costs optimization. As has been said two breakpoints are defined. The model first tries to reach the breakpoint with the largest financial advantage and the largest economics of scale. Only if the total production is either not big enough to fill a slaughtering-house to this breakpoint, or the production is so large it is 
possible to fill more slaughterhouses with this number of slaughters, more than one slaughterhouse is used. Only one other situation can disturb this rule. If all regions have a production, no slaughterhouse can serve all the regions because of the maximum transportation distance of 200 kilometers. Even if the production scale can fill a slaughterhouse till the breakpoint, two slaughterhouses will be used in the optimal solution because of the constraint. If the breakpoint with the largest financial advantages can't be reached, the model tries to fill the slaughterhouses to the other breakpoint. In the result of the scenario's with assumed growth only in the south of The Netherlands almost always only one slaughterhouse is used each year in the optimal solution. This can be explained by the small surface of the area of production.

The slaughtering costs in relation to the year production have a large influence at the number of slaughterhouses used, but which slaughterhouses are used is determined by the minimization of the transportation costs. Within these transportation costs the costs from the farmer to the slaughterhouse are larger and so of more influence than the transportation costs from slaughterhouse to wholesaler. The difference in costs is caused by two reasons. First a wholesaler can always be found near a slaughterhouse and secondly, animal transportation is more expensive then carcass transportation.

The chosen wholesalers in the optimal solution are related to which slaughterhouse is used. Only more than one wholesaler is used when the optimal wholesaler hasn't enough capacity for the whole production of the slaughterhouse in question. Because of the relation between chosen slaughtering-house and wholesaler, the more slaughtering-houses are used in the optimal 


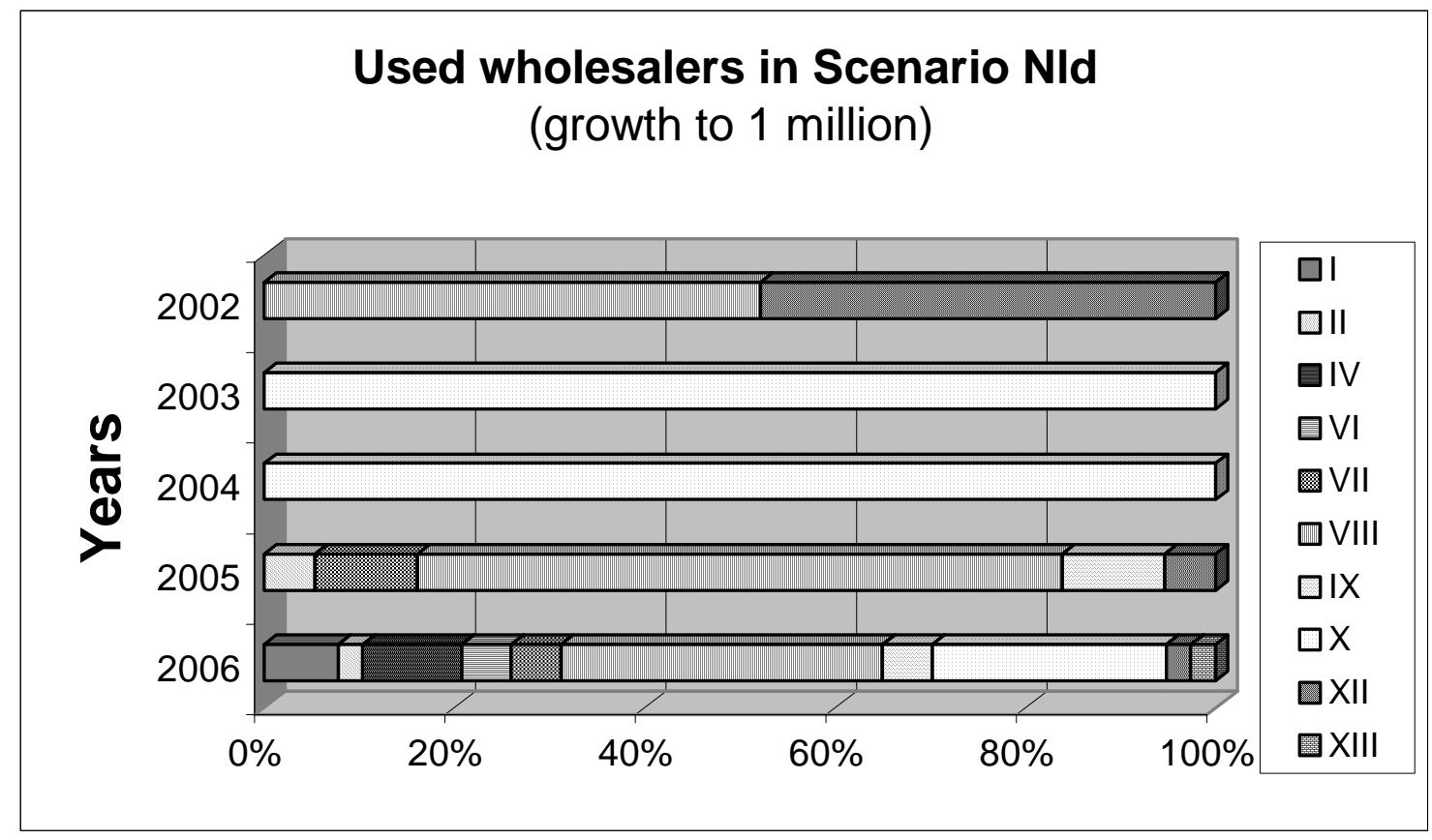

Figure 6: Wholesalers in the optimal solution for each year

solution, the more wholesaler are used also. This can be concluded from a comparison between Figure 5 and Figure 6, wholesalers used for the scenario growth to one million in whole of the Netherlands. Because of this large influence of the shape of the slaughtering costs in combination with the insecurity of correctness of these data a sensitivity analysis has been performed on this subject.

If the variable cost differences between each segment in the cost function are smaller, the economies of scale are also smaller. In some cases the economies of scale of the largest segment (120 000) cannot longer compensate transportation over longer distances.

The number of time each slaughterhouse is used in the optimal solution is shown in Figure 7. The most favorite slaughterhouse was the same for all scenarios, only the second and third optimal solution was different between the two scenarios. In the results of the scenario with production growth in only the south of The Netherlands just three different slaughterhouses were used. 


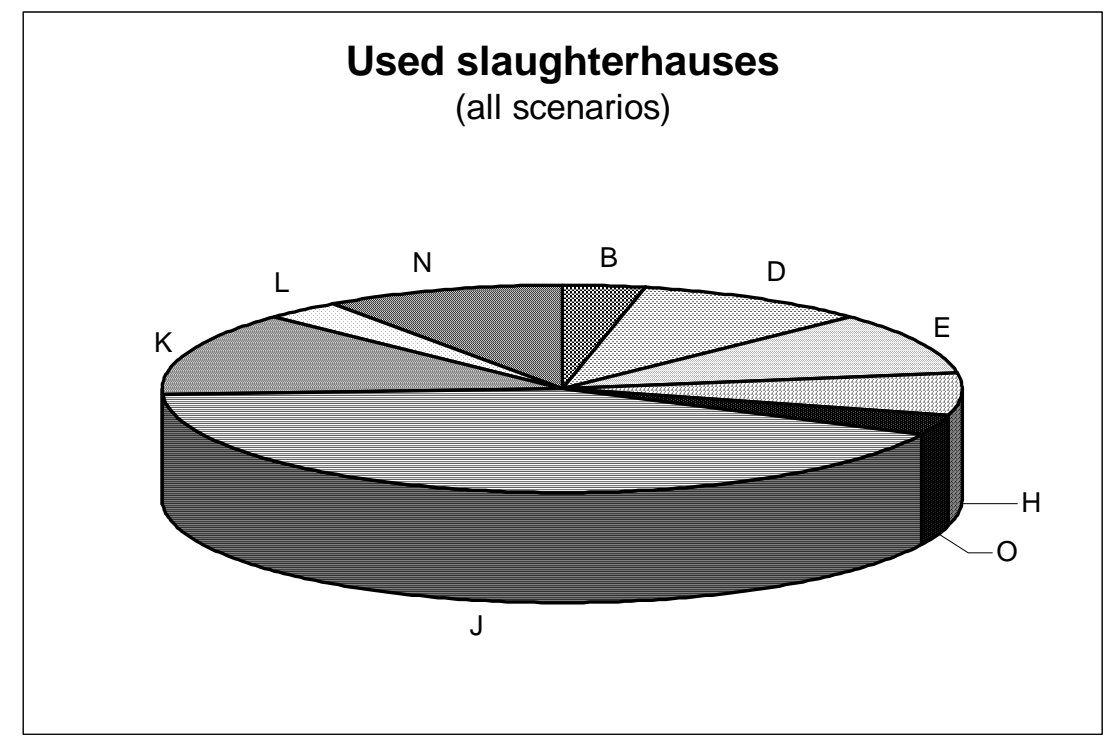

Figure 7: Used slaughterhouses for all scenarios

\section{Conclusions}

With respect to the distribution structure, we can conclude that the slaughtering costs have a high impact on the results. The choice how many slaughtering houses to use is based on the slaughtering costs, whereas the transportation costs influence the choice which slaughterhouse to use. Some potential slaughterhouses are never chosen in a scenario. At least two slaughterhouses have to be chosen because of the Eco Label condition on allowable travel time. Taking all scenarios into account it is possible to select two slaughterhouse locations that are efficient during the five years of investigation. The optimal wholesaler locations depend of course on the used slaughterhouses.

The approach presented in this paper can be used for location problems with the following characteristics:

- discrete multi-level multi-period capacitated facility location problems

- living products or perishable products (no inventory)

- Quick growth of a new brand, competing an already existing brand 
- Facilities are already available due to the existing brand, so no investment costs are required.

Areas of interest to think about are e.g. Eco Label Fruit, Vegetables or Flowers but also green brands in gasoline (Shell Pura), or green electricity. Another area of interest is the growing segment of reused or remanufactured products that are sold as a B-grade flow parallel to the traditional product flows.

\section{Acknowledgement}

The authors thank the management team of De Hoeve b.v. for providing the interesting problem description and their contribution to the research and the Foundation for Agricultural Chain Knowledge (AKK) for financing this research.

\section{References}

Barros, A.I. / Labbé, M. (1994): A general model for the uncapacitated facility and depot location problem, Location Science 3, 173-191

Blonk, T.J. (2001): LCA varkensvleesproductie, Blonk Milieu Advies, Gouda, NL

Canel, C. / Sidhartha, R. (1999): The uncapacitated multi-period facilities location problem with profit maximization, International Journal of Physical Distribution \& Logistics management, Vol. $29(6), 409-433$

Chopra, S. / Meindl, P. (2001): Supply Chain Management, Prentice Hall, Inc., Upper Sadle river, New Jersey

Harkness, J. / Revelle, C. (2003): Facility location with increasing production costs, European Journal of Operational Research, Vol. 125, 1-13.

Heizer, J. / Render, B. (2001), Principles of operations management, Prentice Hall, Inc., Upper sadle river, New Jersey, 308-309. 
O’Kelly, M.E. (1995), Inferred ideal weights for multiple facilities, in: Facility location, eds. Drezner, Z., Springer, New York, 99-102.

Plastria, F. (1995): Continuous location problems, in: Facility location, eds. Drezner, Z., Springer, New York, 225-262.

Schrage, L (1991): LINDO, an optimization modeling system, $4^{\text {th }}$ edition, The scientific Press, USA.

Sule, D.R. (2001): Logistics of facility location and allocation, Marcel Dekker, New York 


\section{Publications in the Report Series Research* in Management}

ERIM Research Program: "Business Processes, Logistics and Information Systems"

\section{3}

Project Selection Directed By Intellectual Capital Scorecards

Hennie Daniels and Bram de Jonge

ERS-2003-001-LIS

http://hdl.handle.net/1765/265

Combining expert knowledge and databases for risk management

Hennie Daniels and Han van Dissel

ERS-2003-002-LIS

http://hdl.handle.net/1765/266

Recursive Approximation of the High Dimensional max Function

Ş. II. Birbil, S.-C. Fang, J.B.G. Frenk and S. Zhang

ERS-2003-003-LIS

http://hdl.handle.net/1765/267

Auctioning Bulk Mobile Messages

S.Meij, L-F.Pau, E.van Heck

ERS-2003-006-LIS

http://hdl.handle.net/1765/274

Induction of Ordinal Decision Trees: An MCDA Approach

Jan C. Bioch, Viara Popova

ERS-2003-008-LIS

http://hdl.handle.net/1765/271

A New Dantzig-Wolfe Reformulation And Branch-And-Price Algorithm For The Capacitated Lot Sizing Problem With Set Up Times

Zeger Degraeve, Raf Jans

ERS-2003-010-LIS

http://hdl.handle.net/1765/275

Reverse Logistics - a review of case studies

Marisa P. de Brito, Rommert Dekker, Simme D.P. Flapper

ERS-2003-012-LIS

http://hdl.handle.net/1765/277

Product Return Handling: decision-making and quantitative support

Marisa P. de Brito, M. (René) B. M. de Koster

ERS-2003-013-LIS

http://hdl.handle.net/1765/278

* A complete overview of the ERIM Report Series Research in Management: $\underline{\text { http://www.erim.eur.nl }}$

ERIM Research Programs:

LIS Business Processes, Logistics and Information Systems

ORG Organizing for Performance

MKT Marketing

F\&A Finance and Accounting

STR Strategy and Entrepreneurship 
Managing Product Returns: The Role of Forecasting

Beril Toktay, Erwin A. van der Laan, Marisa P. de Brito

ERS-2003-023-LIS

http://hdl.handle.net/1765/316

Improved Lower Bounds For The Capacitated Lot Sizing Problem With Set Up Times

Zeger Degraeve, Raf Jans

ERS-2003-026-LIS

http://hdl.handle.net/1765/326

In Chains? Automotive Suppliers and Their Product Development Activities

Fredrik von Corswant, Finn Wynstra, Martin Wetzels

ERS-2003-027-LIS

Mathematical models for planning support

Leo G. Kroon, Rob A. Zuidwijk

ERS-2003-032-LIS

http://hdl.handle.net/1765/332

How and why communications industry suppliers get "squeezed out" now, and the next phase

L-F Pau

ERS-2003-033-LIS

http://hdl.handle.net/1765/317

Financial Markets Analysis by Probabilistic Fuzzy Modelling Jan van den Berg, Uzay Kaymak, Willem-Max van den Bergh

ERS-2003-036-LIS

http://hdl.handle.net/1765/323

WLAN Hot Spot services for the automotive and oil industries :a business analysis or : "Refuel the car with petrol and information , both ways at the gas station "

L-F Pau, M.H.P.Oremus

ERS-2003-039-LIS

http://hdl.handle.net/1765/318

A Lotting Method for Electronic Reverse Auctions

U. Kaymak, J.P. Verkade and H.A.B. te Braake

ERS-2003-042-LIS

http://hdl.handle.net/1765/337

Supply Chain Optimisation in Animal Husbandry

J.M. Bloemhof, C.M. Smeets, J.A.E.E. van Nunen

ERS-2003-043-LIS

A Framework for Reverse Logistics

Marisa P. de Brito and Rommert Dekker

ERS-2003-045-LIS

An assessment system for rating scientific journals in the field of ergonomics and human factors Jan Dul and Waldemar Karwowski

ERS-2003-048-LIS 